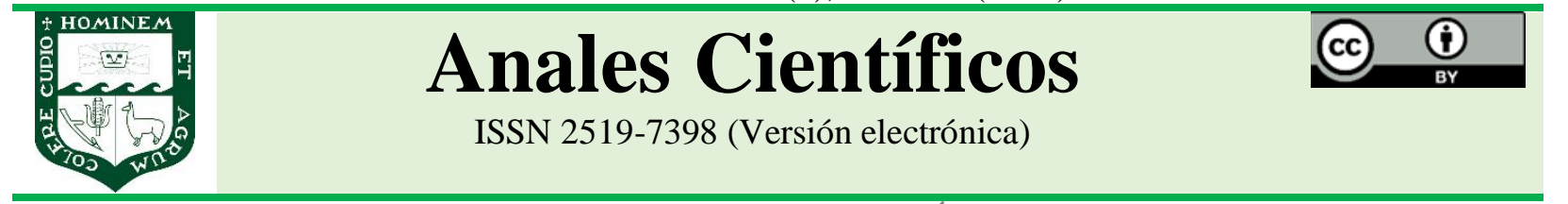

ARTÍCULO ORIGINAL - RESEARCH ARTICLE

http://dx.doi.org/10.21704/ac.v82i1.1749

\title{
FACTORES AGRONÓMICOS ÓPTIMOS PARA LA PRODUCCIÓN COMERCIAL DE CAMOTE (Ipomoea batatas l., cv. Jonathan) EN LA COSTA CENTRAL DEL PERÚ
}

\section{Optimal agronomic factors for commercial sweet potato production (Ipomoea batatas L., cv. Jonathan) on the Peruvian Central Coast}

\author{
Karen Julca-Izquierdo ${ }^{1,2 *}$; $;$ Mayra Mendoza-Cerna1ํㅜ ${ }^{1}$ Vidal Villagómez-Castillo² \\ ${ }^{1}$ Estación Experimental Agraria Chincha, Dirección de Desarrollo Tecnológico Agrario, Instituto Nacional de Innovación \\ Agraria, Chincha, Ica 11750, Perú \\ ${ }^{2}$ Facultad de Agronomía. Dirección de Programa de Investigación en Raíces y Tuberosas, Universidad Nacional Agraria La \\ Molina, La Molina, 15024, Lima, Perú. \\ *E-mail: karenjulcaizquierdo@gmail.com
}

Recibido: 28/05/2020; Aceptado: 29/06/2021; Publicado: 31/08/2021

\begin{abstract}
The objective of the present study was to analyze the effect of three factors as type of seed, seed density and crop fertilization on the yields of commercial sweet potato roots cv. Jonathan. Four variables were analyzed: total root yield, commercial roots yield, non-commercial root yield and total dry matter. The experiment design was a randomized complete block factorial arrangement $2 \mathrm{~S} \times 2 \mathrm{Dx} 2 \mathrm{~F}$, with two levels in each factor: common seed and basic seed, $20 \mathrm{~cm}$ and $40 \mathrm{~cm}$ spacing between cuttings, low and medium fertilization. The results showed that there is no interaction among the factors evaluated. The average planting density factor was statistically higher in all treatments with the spacing of $20 \mathrm{~cm}$ between cuttings; both commercial roots yield and other variables evaluated. In all treatments, commercial yield ensured the economic return of production, T5 treatment (basic seed, $20 \mathrm{~cm}$ spacing between cuttings and low fertilization) showed the highest yield average with $23.35 \mathrm{~kg}$, and the average of the entire harvest of $83.84 \%$ of commercial roots.
\end{abstract}

Keywords: commercial roots; Ipomoea batatas cv. Jonathan; seed quality; planting distance; sweet potato fertilization

RESUMEN

El objetivo de esta investigación fue analizar el efecto de tres factores: tipo de semilla, densidad de siembra y fertilización sobre el rendimiento de raíces de tipo comercial en el cultivo de camote cv. Jonathan. En este sentido, cuatro variables fueron consideradas: rendimiento total de raíces, rendimiento comercial de raíces, rendimiento no comercial y materia seca total. Para el desarrollo de este estudio, se realizó un diseño de bloques completos al azar con arreglo factorial 2Sx2Dx2F, en donde se analizaron dos niveles en cada factor: semilla común y semilla básica, distanciamiento de $20 \mathrm{~cm}$ y $40 \mathrm{~cm}$ entre esquejes, fertilización baja y fertilización media. Los resultados obtenidos mostraron que no existe interacción entre los factores evaluados. El factor densidad de siembra mostró promedios estadísticamente superiores en todos los tratamientos con el distanciamiento de $20 \mathrm{~cm}$ entre esquejes; tanto para el 
rendimiento de raíces de tipo comercial y las otras variables analizadas. En todos los tratamientos se obtuvo un alto rendimiento comercial asegurando el retorno económico de la producción, siendo el tratamiento con más alto rendimiento promedio el T5 (conformado por semilla básica, densidad entre plantas de $20 \mathrm{~cm}$ y fertilización baja) con $23,35 \mathrm{~kg}$ y el promedio de toda la cosecha tuvo un $83,84 \%$ de raíces tipo comercial.

Palabras clave: raíces comerciales; Ipomoea batatas cv. Jonathan; calidad de semilla; distanciamiento de siembra; fertilización en camote

Forma de citar el artículo (Formato APA):
Julca-Izquierdo, K; Mendoza-Cerna, M. \& Villagomez-Castillo, V. (2021). Factores agronómicos óptimos para la producción
comercial de camote (Ipomoea batatas L., cv. Jonathan) en la Costa Central del Perú. Anales Científicos. 82(1),128-138.
http://dx.doi.org/10.21704/ac.v82i1.1749
Autor de correspondencia (*): Karen Julca-Izquierdo. Email: karenjulcaizquierdo@ gmail.com
( Los autores. Publicado por la Universidad Nacional Agraria La Molina.
This is an open access article under the CC BY

\section{INTRODUCCIÓN}

El camote Ipomoea batatas (L.) Lam. es uno de los cultivos alimenticios más importantes a nivel mundial en términos de consumo humano, especialmente en el sub-Sahara de África, algunas partes de Asia y las islas del Pacífico (FAO, 2019). Actualmente, el Centro Internacional de la Papa (CIP) mantiene un total de 3,096 clones de camote de 18 países latinoamericanos y del Caribe, de los cuales el Perú cuenta con 2,016 accesiones (CIP, 2004). La alta producción de este cultivo en países en desarrollo se debe a la diversidad de su uso y bajo costo de producción (Rodríguez-Delfín et al., 2014; Glato et al., 2017).

De acuerdo con lo reportado por Alicai et al. (1999), el camote se propaga vegetativamente mediante semillas-esquejes, aseguran la conservación de las características varietales durante generaciones, siendo ventajoso en un programa de mejoramiento genético. Sin embargo, los esquejes luego de múltiples campañas pueden diseminar enfermedades sistémicas como el virus del enanismo clorótico del camote (Sweetpotato chlorotic stunt virus - SPCSV) transmitido por la mosca blanca y el virus del moteado plumoso del camote (Sweetpotato feathery mottle virus - SPFMV) transmitido por áfidos e infecciones combinadas como la enfermedad del complejo viral del camote (Sweetpotato viral disease - SPVD), la cual es la enfermedad más importante del camote en los trópicos, reduciendo los rendimientos hasta un $90 \%$ en los casos más severos, por ello la importancia de renovar la calidad del material vegetativo con el uso de semilla básica libre de virus (Clark et al., 2012; Kreuze et al., 2000; Gutiérrez et al., 2003). El segmento apical (25 - 35 $\mathrm{cm})$ de los tallos es el mejor para usarse como semilla, ya que éste se recupera más fácilmente del estrés por corte y siembra y crece más rápido que las partes bajas de los tallos (Del Valle, 2012).

Según CIP (2004), la semilla de calidad o libre de virus, es obtenida a través de un proceso que se inicia con la multiplicación rápida (in vitro), seguida de la propagación en viveros o lugares de incremento de plántulas provenientes de laboratorio, para finalmente pasar a la producción de semilla básica de camote en campos de agricultores seleccionados. Siendo, además, una de las prácticas más comunes para evitar infecciones latentes de SPVD, propagar esquejes apicales procedentes del cultivo de meristemos con termoterapia (Clark et al., 2012). En un estudio realizado por Gutierrez et al. (2003), se encontró que, en el valle de Cañete, el complejo viral SPVD tiene la mayor presencia en la zona y junto con otras infecciones virales como el SPFMV y SPCSV, alcanzan un $43 \%$ de infección en las plantas muestreadas. La manifestación de síntomas de estas enfermedades virales se da en el $80 \%$ de las plantas infestadas, por lo que un $20 \%$ puede seguir siendo positivo a la infección, pero mostrarse libre de síntomas, lo que podría favorecer a su incorrecta selección como semilla común y conllevar a la diseminación de las afecciones virales.

Respecto al distanciamiento de siembra, Balmaceda (1968) menciona que los distanciamientos de 20, 30 y $40 \mathrm{~cm}$ entre plantas mostraron significación estadística con respecto al rendimiento de raíces. 
Los estudios en fertilización para el cultivo de camote mostraron que aplicar dosis de $100 \mathrm{~kg}$ de nitrógeno ha-1 se obtuvieron máximos rendimientos de raíces comerciales, mientras que el fósforo con cantidades menores a las dosis de potasio y nitrógeno incrementa el peso promedio y el número de raíces (Marcano y Díaz, 1993). Además, se ha demostrado que el camote es un gran consumidor de potasio y responde bien a su aplicación durante el crecimiento de las raíces reservantes, provocan su incremento en número y peso (Villagómez, 2013).

El Perú siembra en promedio 15,000 ha de camote, de ellas el 70\% de las áreas cultivadas se encuentra en la Costa, donde su rendimiento promedio es de 30 t ha-1, sólo en el departamento de Lima existen 8000 ha aproximadamente, destacan el valle de Cañete como mayor productor nacional (Koo, 2019). Otros importantes departamentos productores son Ancash, Tacna, Arequipa, Lambayeque y Huánuco, siendo la producción nacional de camote equivalente a 17,2 t ha-1 (Villagómez, 2013; MINAGRI, 2018). El cultivar (cv) de camote Jonathan, identificado con el código CIP 420014 (CIP, 2004), fue seleccionado en Chincha en 1985, en la Cooperativa Agraria de Producción Huayna. Este cultivar cuenta con notorias características agronómicas y comerciales que le permitieron no ser reemplazado sino hasta el año 2002 en que fue desarrollado el clon INIA-100, el cual tomó el primer lugar de siembra en las campañas posteriores. El cv. Jonathan registró un rendimiento de raíces de 25.6 (t ha-1), con un peso del follaje de 16,1 (t ha-1) (Díaz, 1990). Así como también un mayor índice de formación de raíces reservantes por semana, presentan un alto potencial de rendimiento además de un elevado contenido de proteína y vitamina A (Salazar et al., 2010; Carpio et al., 2017).

En cuanto a la reducción del rendimiento de raíces reservantes por infecciones virales, para el cv. Jonathan se ha demostrado que no muestra una disminución aparente con virus como el SPFMV, siendo un peligro silencioso en su diseminación, por otro lado, sí muestra reducciones significativas con el SPCSV y reducciones aún más drásticas del rendimiento con la sinergia de ambos en el complejo viral SPVD (Gutierrez et al., 2003). Otro problema importante en camote son los daños por nematodos, se determinaron que en zonas subtropicales destaca la presencia de Meloidogyne incognita y Rotylenchulus reniformis, al mostrar este último la mayor población, ambas especies de nematodos demuestran efectos graves de rajaduras en raíces reservantes (Thomas y Clark, 1983). El cv Jonathan, junto con otros cultivares del grupo de los "apichu" (camotes dulces y acuosos) han sido catalogados como resistentes al nematodo de las agallas, Meloidogyne incognita (Anguiz y Canto-Sáenz, 1991).

Debido a que el cv. Jonathan fue desarrollado hace 35 años, es necesario realizar nuevas investigaciones centradas en la medición de su potencial actual en comparación a los nuevos clones que se estaban desarrollando. Por estos motivos, el objetivo de este estudio fue la obtención del máximo rendimiento de raíces reservantes de la "categoría comercial" en el cv. Jonathan, por ser éstas las preferidas por los acopiadores o mayoristas; ya que las raíces de menor o mayor tamaño no tienen valor comercial (Mariuxi et al., 2011). Para estos fines, se instaló un campo de siembra experimental y se analizó la interacción entre los factores en estudio, demostró cuál de ellos tiene mayor significancia en el rendimiento de raíces comerciales.

\section{MATERIALES Y MÉTODOS}

\section{Localización y condiciones climáticas}

El ensayo se condujo en el campo Guayabo $\mathrm{N}^{\circ} 1$ del campo agrícola experimental de la Facultad de Agronomía de la Universidad Nacional Agraria La Molina (UNALM). Ubicado en la provincia de Lima, siendo sus coordenadas las siguientes: Latitud Sur $12^{\circ} 05^{\prime}$ 6", Longitud Oeste de $76^{\circ} 57^{\prime} 09^{\prime \prime}$ y una altitud de 243,70 m.s.n.m. La duración del experimento fue desde el 12 de diciembre del 2012 hasta el 13 de mayo del 2013. Los datos meteorológicos durante el periodo del experimento fueron registrados por la Estación Meteorológica "Alexander Von Humbold" de la UNALM. Se registró como factor ambiental principal la temperatura, manteniéndose en el inicio de la campaña entre $21.2{ }^{\circ} \mathrm{C}$ y $24.5{ }^{\circ} \mathrm{C}$, durante el desarrollo la temperatura promedio estuvo entre $15.8^{\circ} \mathrm{C}$ y $20^{\circ} \mathrm{C}$, mientras que en el último mes la 
temperatura mínima alcanzó $20.2{ }^{\circ} \mathrm{C}$ y la máxima $23.7^{\circ} \mathrm{C}$. La información meteorológica indica que esta variable se ajustó al rango óptimo para el cultivo según lo descrito por Forquer (1978) y Fersini (1975).

\section{Material vegetal}

La semilla básica utilizada en este trabajo fue donada por el CIP al Programa de Investigación en Raíces y Tuberosas de la UNALM, donde se disponía de campos para la producción de esquejesemilla de camote libre de virus pocos días antes de la instalación del ensayo. El corte de semilla común provino de campos comerciales del Fundo de la UNALM. Para ambos materiales se seleccionaron esquejes apicales de $35 \mathrm{~cm}$ de longitud, con buen vigor y sin afecciones sanitarias, acorde a lo descrito por Del Valle (2012). El tipo de siembra escogido fue "media luna" a un lado del surco, que consiste en enterrar dos tercios del esqueje y dejar expuesto el tercio apical.

\section{Características físicas y químicas del suelo}

La caracterización fisicoquímica se obtuvo al enviar una muestra representativa de suelo al Laboratorio de Análisis de Agua, Suelo, Medio Ambiente y Fertirriego de la Facultad de Ingeniería Agrícola de la UNALM. La muestra fue conseguida de diferentes puntos del área experimental, a una profundidad de 0 a $40 \mathrm{~cm}$.

De acuerdo con lo indicado en la Tabla 1, para un rango de 0 a $40 \mathrm{~cm}$, el suelo presenta una textura franco-arenosa, el cual se caracteriza por tener buena capacidad de retención de humedad, buena aireación y adecuada permeabilidad, aptas para el desarrollo del cultivo (Jaramillo, 2002). El suelo mostró ser ligeramente salino, lo cual no conlleva un problema para el cultivo. Así mismo, tiene un $\mathrm{pH}$ ligeramente alcalino, pero dentro del rango óptimo para el cultivo, con presencia de carbonatos en un nivel medio. Según lo reportado por Marcano y Díaz (1993), los resultados del análisis de suelo bajo las condiciones del estudio demostraron tener niveles adecuados de fertilidad para el cultivo, donde el nivel de fósforo disponible fue medio y el nivel de potasio disponible alto; esto es fundamental para el desarrollo de raíces reservantes (Villagómez, 2013). La capacidad de intercambio catiónico (CIC) de suelo es de nivel bajo, igualmente los cationes calcio, potasio y sodio. Mientras que solo el catión magnesio está a un nivel normal. Lo que justifica las dosis de nitrógeno, fósforo y potasio aplicadas en esta investigación.

Tabla 1. Análisis físico y químico de caracterización de suelo.

\begin{tabular}{|c|c|c|c|c|c|c|}
\hline \multicolumn{5}{|c|}{ Análisis Físico } & \multirow[t]{2}{*}{ pH (1:1) } & \multirow[t]{2}{*}{ CE (1:1) dSm-1 } \\
\hline Textura & Arena $\%$ & Limo $\%$ & Arcilla \% & M.O. (\%) & & \\
\hline Fr. A. & 59 & 25 & 16 & 1,61 & 7,36 & 1,04 \\
\hline \multicolumn{7}{|c|}{ Análisis Químico } \\
\hline $\mathrm{P}(\mathrm{ppm})$ & $\mathrm{K}(\mathrm{ppm})$ & $\mathrm{Ca}+2$ & $\mathrm{Mg}+2$ & $\mathrm{~K}+$ & CIC & $\mathrm{CaCO} 3(\%)$ \\
\hline 12,8 & 276 & 9,21 & 1,67 & 0,47 & 11,84 & 3,10 \\
\hline
\end{tabular}

\section{Control Fitosanitario}

A los 27 días después de la siembra (d.d.s.) se observaron poblaciones bajas de Empoasca fabalis, Bemisia tabaci de manera dispersa en campo y en menor magnitud de Microthyris anormalis, Pebops sp., y Myzus persicae, lo cual llevó a la decisión de aplicar un control químico general en esta etapa del cultivo. Cabe resaltar que no hubo poblaciones vectores que ejercieran una gran presión de inóculo, debido a la previa rotación de cultivos y al descanso del campo donde se llevó a cabo el experimento.

\section{Factores en estudio y diseño estadístico}

En este experimento se evaluaron tres factores del cultivo (1) Tipos de semilla, S1: semilla comercial y S2: semilla básica (2) Densidad de siembra entre esquejes, D1: $20 \mathrm{~cm}$ y D2: $40 \mathrm{~cm}$; y (3) Nivel de fertilización N-P-K, F1, baja: 60-40-100 y F2, media: 80-60-120. Por otro lado, se usó como fuente de nitrógeno a la urea $(46 \%$ de $\mathrm{N})$, al superfosfato Triple (46\% de PO2) como fuente de fósforo y como fuente de potasio se utilizó el Sulfato de potasio (50\% K2O). El diseño estadístico empleado para el análisis de datos fue el de bloques completos al azar 
(DBCA) en arreglo factorial $2 \mathrm{~S} \times 2 \mathrm{Dx} 2 \mathrm{~F}$, lo que permitió la combinación de los tres factores evaluados con dos niveles en cada factor; obteniéndose un total de 8 tratamientos (Tabla 2). Asimismo, se realizaron cuatro repeticiones por tratamiento, con un total de 32 parcelas experimentales. Cada parcela fue conformada por 3 surcos de $1 \mathrm{~m}$ de ancho y $4 \mathrm{~m}$ de largo (12 m2). Dentro de cada surco se sembraron 20 esquejes (D1 $=20 \mathrm{~cm})$ y 10 esquejes $(\mathrm{D} 1=40 \mathrm{~cm})$ según el tratamiento correspondiente. El análisis estadístico se realizó con el programa SAS V.6 (SAS, 2014).

Tabla 2. Descripción de los tratamientos según las combinaciones de los factores en estudio.

\begin{tabular}{cccc}
\hline Trat. & Semilla (S) & Densidad (D) & Fertilización (F) \\
\hline T1 & S1: comercial & D1: $20 \mathrm{~cm}$. & F1: baja \\
T2 & S1: comercial & D1: $20 \mathrm{~cm}$. & F2: media \\
T3 & S1: comercial & D2: $40 \mathrm{~cm}$. & F1: baja \\
T4 & S1: comercial & D2: $40 \mathrm{~cm}$. & F2: media \\
T5 & S2: básica & D1: $20 \mathrm{~cm}$. & F1: baja \\
T6 & S2: básica & D1: $20 \mathrm{~cm}$. & F2: media \\
T7 & S2: básica & D2: $40 \mathrm{~cm}$. & F1: baja \\
T8 & S2: básica & D2: $40 \mathrm{~cm}$. & F2: media \\
\hline
\end{tabular}

\section{Evaluaciones agronómicas}

Entre las variables analizadas estadísticamente al momento de la cosecha se consideró, el rendimiento total de raíces reservantes (Rdto. RR) en kilogramos $(\mathrm{kg})$, en los surcos centrales de cada parcela experimental. A través de una media aritmética se obtuvo el rendimiento promedio por tratamiento, con este promedio de las cuatro repeticiones se trabajaron los análisis estadísticos de análisis de varianza (ANVA) y comparaciones de medias Duncan. Dentro del total del Rdto. RR, se hizo una clasificación (en $\mathrm{kg}$ ) entre rendimiento de raíces tipo comercial (Rdto. RC), donde las raíces fueron clasificadas en tipo comercial (peso entre $80-200$ g) y sin daños visibles por plagas, enfermedades o mecánicos; y en raíces tipo no comercial (Rdto. NC.), siendo aquellas raíces con pesos menores a 80 $\mathrm{g}$, mayores a $200 \mathrm{~g}$ o que presenten algún tipo de daño estético. Luego de obtenidos los rendimientos por categorías en kilogramos, se obtuvo el promedio total de la cosecha del porcentaje de raíces reservantes tipo comercial (\% Rdto RC), se calculó al promediar el rendimiento de raíces reservantes tipo comercial obtenido entre todos los tratamientos y repeticiones respecto a la cosecha total (Rdto. RR). El contenido de materia seca (CMS) promedio por tratamiento es un parámetro importante en la poscosecha y se determinó por el método de secado en estufa. Se comparó el peso seco final con el peso fresco inicial, obteniéndose el total de materia seca promedio en $\mathrm{kg}$ por tratamiento. En base a estos datos, se obtuvo un porcentaje promedio de materia seca en el total de la cosecha (\% MS).

Entre tanto, otros valores agronómicos fueron evaluados durante el experimento, como el porcentaje de prendimiento (PP), el cual equivale al porcentaje de plantas establecidas y vigorosas a los 16 d.d.s. respecto a las plantas sembradas inicialmente, a través de un conteo simple en los surcos centrales de cada parcela por tratamiento. Para proyectar la fecha de cosecha se realizó el muestreo de plantas en tres momentos, a los 72, 92 y 128 d.d.s, y extraer una planta de un surco lateral al azar por cada parcela y analizar la longitud y pesos de la parte aérea, radicular y total de la planta. Al final de la campaña se contabilizó el número total de plantas adultas por parcela experimental, a fin de determinar el porcentaje de sobrevivencia.

\section{RESULTADOS Y DISCUSIÓN}

\section{Resultados estadísticos}

Tras realizarse el diseño DBCA, se obtuvieron los valores y el análisis ANVA para cada variable según los tratamientos descritos (Tabla 3). Para la variable Rdto. RR se determinó que el factor densidad de siembra fue altamente significativo $(\alpha=0.01)$, lo que indica que el rendimiento final de raíces reservantes difiere estadísticamente para cada nivel de este factor. Las interacciones entre los factores evaluados resultan ser no significativas, de igual manera tampoco existe significancia para los bloques. El coeficiente de variabilidad (CV) en el análisis estadístico del Rdto. RR fue de 13,94\%, el cual es un valor aceptado para trabajos realizados en campo, donde los CV deben ser menor al 30\% (Sanchez y Rivera, 2018). 
Tabla 3. Análisis de varianza para las variables rendimiento total de raíces (Rdto.RR), raíces comerciales (Rdto.RC), no comercial (Rdto.NC) y materia seca (CMS).

\begin{tabular}{lcccccccc}
\hline & \multicolumn{2}{c}{ Rdto. RR } & \multicolumn{2}{c}{ Rdto. RC } & \multicolumn{2}{c}{ Rdto. NC } & \multicolumn{2}{c}{ CMS } \\
Fuente de variación & Pr $>$ F & ANVA & Pr $>$ F & ANVA & Pr $>$ F & ANVA & Pr $>$ F & ANVA \\
\hline Bloques & 0,8576 & NS & 0,8766 & NS & 0,9653 & NS & 0,7307 & NS \\
Semilla (S) & 0,3307 & NS & 0,6142 & NS & 0,5013 & NS & 0,1052 & NS \\
Densidad (D) & $0,0001 * *$ & SIG & $0,0003^{* *}$ & SIG & 0,063 & NS & $0,0001 * *$ & SIG \\
Fertilización (F) & 0,1767 & NS & 0,3098 & NS & 0,697 & NS & 0,3772 & NS \\
S*D*F & 0,5948 & NS & 0,2269 & NS & 0,4614 & NS & 0,5322 & NS \\
Promedio & 18.91688 & & 15.84906 & & 3.067813 & & 4.444 & \\
C.V. & 13.94467 & & 18.37762 & & 54.14522 & & 17.4239 & \\
\hline
\end{tabular}

** Nivel de significancia de 0.01

SIG: significativo

Por otro lado, las comparaciones de medias Duncan (Tabla 4), confirman los resultados obtenidos en el ANVA, en donde se obtienen grupos estadísticamente distintos en los niveles del factor densidad de siembra. Se observan medias superiores de rendimientos en los tratamientos con distanciamiento de $20 \mathrm{~cm}$ entre esquejes respecto a los tratamientos de $40 \mathrm{~cm}$, con valores de $21,75 \mathrm{~kg}$ y $16,08 \mathrm{~kg}$ respectivamente (Tabla 4). Estos resultados coinciden con lo reportado por Balmaceda (1968) quien obtuvo los mayores rendimientos por hectárea, con distanciamiento entre los 15 y $25 \mathrm{~cm}$. En este sentido, todas las variables evaluadas mostraron rendimientos ligeramente superiores con la fertilización baja (F1), por lo que estimamos que agregarle una dosis media (F2) a condiciones de fertilidad inicial sería contraproducente para el rendimiento.

Tabla 4. Promedios de rendimiento (kg/tratamiento) de raíces totales (Rdto. RR), raíces comerciales (Rdto. RC), raíces no comerciales (Rdto. NC), contenido de materia seca (CMS) y comparaciones Duncan para cada factor evaluado.

\begin{tabular}{|c|c|c|c|c|c|c|c|c|c|}
\hline \multirow[b]{2}{*}{$\begin{array}{l}\text { Factores } \\
\text { evaluados }\end{array}$} & \multirow[b]{2}{*}{ Niveles de cada factor } & \multicolumn{2}{|c|}{ Rdto. RR } & \multicolumn{2}{|c|}{ Rdto. RC } & \multicolumn{2}{|c|}{ Rdto. NC } & \multicolumn{2}{|c|}{ CMS } \\
\hline & & Promedio & Duncan & Promedio & Duncan & Promedio & Duncan & Promedio & Duncan \\
\hline Tipo de & S1: semilla común & 19,381 & A & 16,113 & A & 3,268 & $\mathrm{~A}$ & 4,675 & $\mathrm{~A}$ \\
\hline \multirow[t]{2}{*}{ semilla } & S2: semilla básica & 18,452 & A & 15,586 & A & 2,866 & A & 4,212 & A \\
\hline & D1: $20 \mathrm{~cm}$ entre plantas & 21,752 & A & 18,108 & A & 3,644 & A & 5,132 & A \\
\hline $\begin{array}{l}\text { Densidad de } \\
\text { siembra }\end{array}$ & D2: $40 \mathrm{~cm}$ entre plantas & 16,081 & B & 13,590 & B & 2,491 & A & 3,755 & B \\
\hline \multirow{2}{*}{$\begin{array}{l}\text { Dosis de } \\
\text { fertilizacion }\end{array}$} & F1: fertilización baja & 19,568 & A & 16,385 & A & 3,183 & A & 4,567 & A \\
\hline & F2: fertilización media & 18,265 & A & 15,313 & A & 2,951 & A & 4,320 & A \\
\hline
\end{tabular}

Letras mayúsculas iguales indican que no hay diferencias significativas entre los niveles para cada factor evaluado $(\mathrm{p}<0,05)$

Estos resultados se basaron en que la planta desarrollará una masa foliar excedente que actúa como consumidora de fotosintatos disminuyendo su translocación a las raíces (Villalpando, 1993). Para la variable Rdto. RC, sólo el factor densidad de siembra tuvo alta significancia como se demuestra en el análisis ANVA (Tabla 3) y la media de los rendimientos Duncan (Tabla 4), los tratamientos con una distancia de siembra de $20 \mathrm{~cm}$ entre esquejes fueron superiores a los de $40 \mathrm{~cm}$ entre esquejes, con valores de 18,10 y $13,59 \mathrm{~kg}$ respectivamente. Mientras tanto, para la variable Rdto. NC, no se encontraron diferencias significativas en ninguno de los tres factores evaluados (Tabla 3), evidenciaron que el rendimiento de esta variable estaría sujeto a otros factores externos no analizados en el presente trabajo de investigación. 
En el caso del CMS promedio por tratamiento, el ANVA (Tabla 3) indica que el factor densidad de siembra obtuvo un resultado altamente significativo, lo que indica que el CMS en raíces reservantes difiere estadísticamente para cada nivel de este factor. Se resalta la media general de $4.44 \mathrm{~kg}$ de materia seca contenida en la raíz por surco central de evaluación. Mediante las comparaciones de medias con la Prueba Duncan (Tabla 4) se obtienen dos grupos diferenciados estadísticamente para el factor densidad de siembra, concordar con el ANVA, obteniéndose una media de $5,13 \mathrm{~kg}$ en aquellas plantas sembradas a $20 \mathrm{~cm}$ entre esquejes con respecto a una media de $3,75 \mathrm{~kg}$ en las plantas sembradas cada $40 \mathrm{~cm}$. Acorde a lo reportado por Castillo et al. (2014), a mayor número de plantas por área aumenta el contenido de biomasa total, quienes con distancias de siembra en un rango entre 15 a 25 cm, obtuvieron la máxima acumulación de sustancias de reserva.

Bajo las condiciones de las parcelas, la variable materia seca presentó grupos estadísticamente homogéneos en los factores tipo de semilla y nivel de fertilización, sin embargo, cabe resaltar que el mayor promedio de materia seca para el factor tipo de semilla fue de $4,67 \mathrm{~kg}$, con semilla común y respecto al factor fertilización, la media superior fue de 4,56 kg, con el nivel bajo. Como anteriormente se mencionó en el caso de la fertilización media, la planta desarrollará un mayor índice de área foliar (IAF), porque se consumirán más carbohidratos en la parte aérea de los que se almacenan en las raíces (Villalpando y Ruiz, 1993).

\section{Valores agronómicos obtenidos}

El PP obtenido a los 16 d.d.s. fue de 99,37\% el cual concuerda con la precocidad y rusticidad característica del cultivar Jonathan (CIP, 2004). Estos valores son característicos de esta variedad, es por ello que el cv Jonathan no ha tenido un reemplazo adecuado como variedad de camote amarillo en cuanto a su calidad de pulpa, calidad de cocción y rusticidad, la que favorece su alto prendimiento a la siembra en casi todos los terrenos. En cuanto a los valores medidos a lo largo del crecimiento (Tabla S1): en el primer muestreo (72 d. d. s.) se evidenció algunas raíces con rajaduras relacionadas a la insuficiente formación de raíces reservantes.

En el segundo muestreo (92 d.d.s.) se observó un aumento normal en los pesos del follaje y en la longitud de las plantas, mientras que en el tercer muestreo (128 d.d.s.) se observó un decrecimiento en la longitud y peso de la parte aérea, además un notable aumento en el peso de la parte radicular en la mayoría de las plantas. Basados en estos datos, se programó la fecha de cosecha en no más de 30 días posteriores a los muestreos. Esto coincide con lo descrito por Mariuxi et al. (2011). Los resultados reafirman que al sobrepasar el área foliar efectiva durante el crecimiento del cultivo existirá una menor distribución de fotosintatos hacia los órganos de reserva (Rodríguez-Delfín et al. 2014). Asimismo, el porcentaje de sobrevivencia del cultivo fue del $98,54 \%$ ya que de un total de 1440 plantas sembradas llegaron a cosechar 1419, con ello se confirma la alta rusticidad del cultivo (CIP, 2004).

El tratamiento con mayor Rdto. RR equivale a 23,35 $\mathrm{kg}$ en el T5, conformado por semilla básica, densidad entre plantas de $20 \mathrm{~cm}$ y fertilización baja, y el rendimiento más bajo corresponde al T8 con $14,9 \mathrm{~kg}$, conformado por semilla básica, densidad de $40 \mathrm{~cm}$ y fertilización media (Figura 1). En el caso del Rdto. RC, el valor más alto equivale a $20,27 \mathrm{~kg}$ en el T5 (Figura 1), en este caso formado por semilla básica, densidad de $20 \mathrm{~cm}$ y fertilización baja. Sin embargo, aquellos tratamientos con semilla comercial, pero con la misma distancia de $20 \mathrm{~cm}$ entre esquejes, presentan también buenos rendimientos, 18,30 y $17,97 \mathrm{~kg}$, correspondientes al T1 y T2 respectivamente. Por otro lado, los tratamientos T7 y T8 con semilla básica y distanciamiento de $40 \mathrm{~cm}$, presentaron mayor rendimiento por planta, pero menor rendimiento promedio con 13,19 y $13,00 \mathrm{~kg}$ respectivamente. 


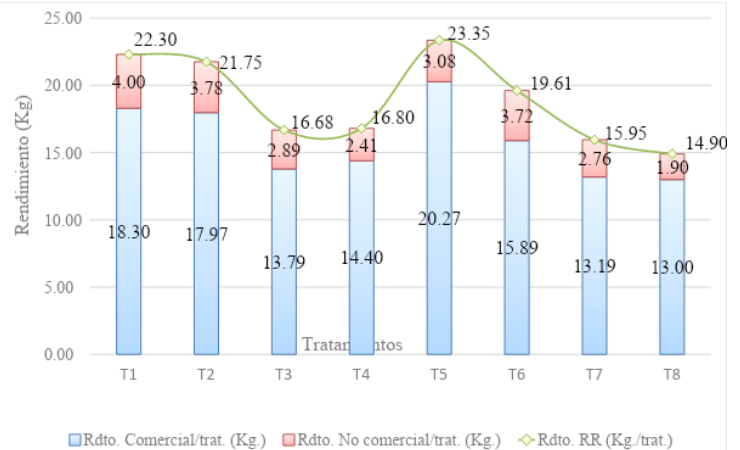

Figura 1. Promedios de rendimiento de raíces totales (Rdto. RR), raíces comerciales (Rdto. RC), raíces no comerciales (Rdto. NC) en kg/tratamiento.

En el Rdto. NC, no se observaron daños visibles por plagas o enfermedades, siendo otras las causas de descarte, como rajaduras y daño mecánico a la cosecha. El promedio más alto fue de 4,0 $\mathrm{kg}$ en el T1 y el más bajo de 1,91 kg en T8 (Figura 1). Las raíces con rajaduras son el síntoma característico de daño por nematodos en camote, relacionado a la especie más predominante en la región, el Rotylenchulus reniformis (Thomas y Clark, 1983). Aunque para la presente investigación no se realizó un análisis nematológico del suelo, por lo que no se tiene evidencia para relacionar los síntomas observados a éstos patógenos.

Ha sido posible determinar la proyección del rendimiento promedio (Rdto. Total) en $\mathrm{t}$ ha-1 para cada tratamiento mediante un factor de estandarización, donde el mayor rendimiento corresponde a 58,38 t ha- 1 en el T5 y de forma decreciente a éste, los tratamientos T1, T2, T6, T4, T3 y T7 con 55,75; 54,38; 49,03; 42,00; 41,69 y 39,88 t ha-1 respectivamente, siendo el tratamiento con menor rendimiento el T8 con 37,25 tha-1 (Tabla 5). Se obtuvieron rendimientos por hectárea superiores al promedio nacional, compitiendo con nuevos clones promisorios estudiados por Cantoral et al. (2020). A la cosecha, el \% Rdto. RC por tratamiento, permitió calcular el valor promedio de $83,84 \%$, demostró alto rendimiento y valor comercial del cultivo del camote. Estos resultados concuerdan con lo reportado por Del Carpio (1987) y La Revista Agraria (2004).
En la determinación del CMS por tratamiento, se obtuvo el porcentaje de materia seca (\%MS) al aplicar un factor de estandarización por tratamiento, mostrándose los valores $24,97 \% ; 24,20 \% ; 23,63 \%$; $23,33 \% ; 23,25 \% ; 23,18 \% ; 23,16 \%$ y $22,06 \%$, perteneciente a los tratamientos T1, T2, T4, T3, T7, T6, T8 y T5 respectivamente (Tabla 6). En relación $\%$ MS, se obtiene una media general de $23,47 \%$ para el cv. Jonathan, al estar dentro del rango descrito de materia seca para esta especie según Marcano \& Díaz (1993). En este sentido, Castillo et al. (2014) indica que el contenido de materia seca varía ampliamente debido a factores tales como la variedad, la localidad, el clima, la duración del día, el tipo de suelo, la incidencia de plagas, enfermedades y las prácticas de cultivo; en sus estudios hallaron contenidos de materia seca entre $18,7 \%$ y $27,6 \%$ (con una media de $22,4 \%$ ) que coincide con lo observado en este estudio $(23,47 \%)$, señala también que el contenido de materia seca está relacionado con la aceptación del consumidor final. En general, variedades de camote con altos contenidos de materia seca entre 22 y $26 \%$ son mejor aceptadas por la población (Castillo et al., 2014).

Es importante resaltar que, bajo condiciones del experimento, las variables Rdto. RR, Rdto. RC, Rdto NC y CMS, el factor tipo de semilla resultó no ser significativo, probablemente debido a que los campos de la UNALM en los que se seleccionaron el material de semilla común fueron manejados con prácticas adecuadas como rotación de cultivos y control oportuno de insectos vectores, que evitan la contaminación del material con complejos virales, manifestando una calidad agronómica muy similar a la semilla básica utilizada. Sin embargo, existe un alto riesgo de usar semilla común en lugares donde la producción de camote es recurrente, como el Valle de Cañete y otros en Costa central, sumada a la finalidad de ahorrar costos y donde el agricultor produce su propia semilla sin ningún control sanitario. Esto puede llevar a reducciones en el rendimiento de raíces reservantes entre el 43,55\% al $72,24 \%$ en el cv. Jonathan debido a infecciones con SPCSV y SPVD respectivamente (Gutierrez et al., 2003). 
Tabla 5. Rendimiento proyectado (en $\mathrm{t} \mathrm{ha}^{-1}$ ) de raíces reservantes totales, comerciales, no comerciales por tratamiento y porcentaje (\%) de raíces comerciales por tratamiento.

\begin{tabular}{|c|c|c|c|c|c|c|}
\hline Trat. & $\begin{array}{c}\text { Rdto. * } \\
\text { Comercial/trat. } \\
(\mathrm{kg}) \\
\end{array}$ & $\begin{array}{c}\text { Rdto. }{ }^{* *} \\
\text { Comercial }(\mathrm{Tn} \\
\left.\text { ha }^{-1}\right) \\
\end{array}$ & $\begin{array}{c}\text { Rdto. No * } \\
\text { comercial/trat. } \\
(\mathrm{kg})\end{array}$ & $\begin{array}{c}\text { Rdto. No } * * \\
\text { comercial (Tn ha } \\
1 \text { ) }\end{array}$ & $\begin{array}{l}\text { Rdto. Total (Tn } \\
\left.\text { ha }^{-1}\right)^{* *}\end{array}$ & $\begin{array}{l}\text { Rdto. RC } \\
\qquad \%)\end{array}$ \\
\hline $\mathrm{T} 1$ & 18,30 & 45,75 & 4,00 & 10,00 & 55,75 & 82,06 \\
\hline $\mathrm{T} 2$ & 17,97 & 44,93 & 3,78 & 9,45 & 54,38 & 82,34 \\
\hline $\mathrm{T} 3$ & 13,79 & 34,46 & 2,89 & 7,23 & 41,69 & 83,13 \\
\hline $\mathrm{T} 4$ & 14,40 & 35,98 & 2,41 & 6,01 & 42,00 & 85,52 \\
\hline $\mathrm{T} 5$ & 20,27 & 50,68 & 3,08 & 7,70 & 58,38 & 85,76 \\
\hline T6 & 15,89 & 39,73 & 3,72 & 9,29 & 49,03 & 81,53 \\
\hline $\mathrm{T} 7$ & 13,19 & 32,96 & 2,77 & 6,91 & 39,88 & 83,48 \\
\hline \multirow[t]{2}{*}{$\mathrm{T} 8$} & 13,00 & 32,49 & 1,91 & 4,76 & 37,25 & 86,93 \\
\hline & & & & & Promedio & 83,84 \\
\hline
\end{tabular}

* Área de $4 \mathrm{~m} 2$ (surcos centrales de cada parcela)

** Proyección realizada a 1 hectárea

Tabla 6. Contenido de materia seca $(\mathrm{kg})$ y porcentaje promedio por tratamiento.

\begin{tabular}{ccc}
\hline Tratamientos & CMS (kg)/trat. & \% MS \\
\hline T1 & 5,56 & 24,97 \\
T2 & 5,28 & 24,20 \\
T3 & 3,88 & 23,33 \\
T4 & 3,97 & 23,63 \\
T5 & 5,13 & 22,06 \\
T6 & 4,56 & 23,18 \\
T7 & 3,70 & 23,25 \\
T8 & 3,46 & 23,16 \\
\hline Promedio & 4,44 & 23,47
\end{tabular}

\section{CONCLUSIONES}

El factor densidad de siembra resultó altamente significativo para las variables rendimiento total de raíces de almacenamiento, rendimiento de raíces tipo comercial y contenido de materia seca. Se obtuvieron promedios de rendimiento superiores con la distancia entre plantas de $20 \mathrm{~cm}$ vs distancia de $40 \mathrm{~cm}$, por lo que se recomienda utilizar mayor cantidad de plantas sembradas por superficie para obtener mejor retorno económico para el agricultor. Bajo las condiciones medioambientales y ecológicas del experimento; los factores tipo de semilla y nivel de fertilización, así como la interacción entre los tres factores evaluados y los tratamientos, no resultan estadísticamente significativos para el rendimiento. Sin embargo, basados en el peligro potencial de afecciones por virus, se recomienda usar semilla básica provista por un organismo autorizado como lo es el CIP o el Instituto Nacional de Innovación Agraria (INIA), especialmente en valles donde pueda existir una gran población de insectos vectores específicos. Asimismo, se recomienda no exceder las unidades de fertilizantes recomendadas en las dosis de fertilización, para evitar disfunciones en la fisiología de la planta. En toda la cosecha, se obtuvo un promedio de $83,84 \%$ de raíces tipo comercial, el más alto rendimiento se obtuvo con el $\mathrm{T} 5$ con $23,35 \mathrm{~kg}$. Se mantiene además un alto contenido de materia seca de $23,47 \%$. Se concluye que el cultivar Jonathan, siendo un cultivar antiguo, mantiene a la actualidad sus características agronómicas y comerciales superiores que lo hicieron resaltar como una de las mejores opciones de cultivo de camote amarillo dulce para el agricultor de las zonas productivas del Perú.

\section{Conflictos de intereses}

Los autores firmantes del presente trabajo de investigación declaran no tener ningún potencial conflicto de interés personal o económico con otras 
personas $\mathrm{u}$ organizaciones que puedan influir indebidamente con el presente manuscrito.

\section{Contribuciones de los autores}

Preparación y ejecución: KJ y VVC Desarrollo de la metodología: KJ, MM y VVC. Concepción y diseño: KJ y VVC Edición del artículo: KJ y MM Supervisión del estudio: VVC.

\section{LITERATURA CITADA}

- Alicai, T., Fenby, N.S., Gibson, R.W., Adipala, E., Vetten, H.J., Foster, G.D., \& Seal, S.E. (1999). Occurrence of two serotypes of sweet potato chlorotic stunt virus in East Africa and their associated differences in coat protein and HSP70 homologue gene sequences. Plant Pathol. 48, 718-726.

- Anguiz R., \& Canto-Sáenz M. (1991). Reacción de cultivares de camote (Ipomoea batatas (L.) Lam.) a Pratylenchus flakkensis Seinhorst. Nematrópica 21(2), 197-201.

- Balmaceda C. (1968). Estudio de Tres Densidades de Siembra y Cuatro Niveles de Nitrógeno en el cultivo del camote. Tesis UNALM. Lima, Perú.

- Cantoral E., Chavez A., \& Flores A. (2020). Nueva variedad de camote (Ipomoea batatas L. Lam.) con mejores características agronómicas y comerciales. Scientia Agropecuaria 11(1), 3948.

- Carpio, R.V., Sotelo, A., \& Grüneberg, W.J. (2017). Contenido de $\beta$-Caroteno, Hierro y Zinc, Efecto de Almacenamiento y Tipo de Cocción de Genotipos de Camote (Ipomoea batatas L.). Revista de Investigaciones Veterinarias del Perú 28(2), 242-254.

- Castillo, R., Brenes, A., Esker, P., \& Gómez, A. (2014). Evaluación Agronómica de trece genotipos de camote (Ipomoea batatas L.). Agronomía Costarricense 38(2), 67-81.

- Centro Internacional de la Papa. [CIP]. (2004). El camote: un gigante dormido. Publicaciones del CIP. Lima.

- Clark, C., Davis, J., Abad, J., Cuellar, W., Fuentes, S., Kreuze, J., William R., Mukasa, S., Tugume, A., Tairo, F., \& Valkonen J. (2012).
Sweetpotato Viruses: 15 Years of Progress on Understanding and Managing Complex Diseases. The American Phytopathological Society. Plant Disease. 96(2),168-185. https://doi.org/10.1094/PDIS-07-11-0550.

- Del Carpio, B.R. (1987). Investigaciones y experiencias en el cultivo del camote en la Costa Central del Perú. Lima, Perú.

- Del Valle, L. (2012). Producción, multiplicación y manejo de propágulos de batata de sanidad controlada. 1ra Edición. INTA. Argentina. 78 pp.

- Díaz, L. (1990). El cultivo del camote en el Perú. II Curso Internacional sobre el cultivo del camote. Argentina. INTA-CIP.

- Forquer, F. (1978). La batata (camote): estudio de la planta y su producción comercial. Editorial HemisferioSur S.A. primera edición. Buenos Aires, Argentina. 144 pp.

- Fersini, A. (1975). El cultivo de la batata. Editorial Diana S.A. Primera edición. México 124 pp.

- Food and Agriculture Organization of the United Nations [FAO]. (2019). FAOSTAT. FAO. Disponible en: http://www.fao.org/faostat/en/\#data

- Glato, K., Aidam, A., Ardo, N., Bassirou. D., Couderc, M., Zekraoui, L., Scarcelli, N., Barnaud, A., \& Vigouroux, Y. (2017). Structure of sweet potato (Ipomoea batatas) diversity in West Africa covaries with a climatic gradient. PLoS ONE 12(5), e0177697.

- Gutiérrez, D.L., Fuentes, S., \& Salazar, L.F. (2003). Sweetpotato Virus Disease (SPVD): Distribution, Incidence, and Effect on Sweetpotato Yield in Peru. Plant Dis. 87(3),297302 .

https://doi.org/10.1094/PDIS.2003.87.3.297

- Jaramillo, P. (2002). Introducción a la ciencia del suelo. Recuperado de: https://repositorio.unal.edu.co/handle/unal/7008 5.

- Kreuze, J. F., Kareijea, R.F., Gibson, R. W., \& Valkonen, J.P.T. (2000). Comparison of coat protein gene sequences show that East African isolates of Sweet potato feathery mottle virus form a genetically distinct group. Arch. Virol. $145,567-574$. 
- Koo, W. (2019). Camote Perú exportación 2019 marzo. AgrodataPerú. Revisado en abril del $2019 . \quad$ Disponible en: https://www.agrodataperu.com/2019/04/camote -peru-exportacion-2019-marzo.html

- La Revista Agraria. (2004). El camote: su sabor y su valor. La Revista Agraria. 60. Noviembre del 2004. Lima-Perú.

- Mariuxi, C., Corbeña, G., Álvarez, H., Castro, L., \& Cárdenas, F. (2011). Caracterización agronómica de germoplasma de camote (Ipomoea batatas L.) en Manabí. Espam Ciencia 2(2), 37-43.

- Marcano A., J., \& Díaz L. (1993). Efecto de la Aplicación de Seis Combinaciones de N, P, K sobre el Rendimiento de Raíces y Follaje de Batata. Tesis de Estación Experimental Yaracuy. Venezuela.

- Ministerio de Agricultura y Riego [MINAGRI]. (2018). Encuesta Nacional de Intenciones de Siembras 2018. Disponible en: https://www.midagri.gob.pe/portal/orientacionproductor

- Moyer, J. W., \& Salazar, L.F. (1989). Viruses and virus like diseases of sweet potato. Plant Dis. 73, 451-455.

- Rodríguez-Delfín, A., Posadas, A., \& Quiroz, R. (2014). Rendimiento y absorción de algunos nutrimentos en plantas de camote cultivadas con estrés hídrico y salino. Revista Chapingo Serie Horticultura 20(1), 19-28.

- Salazar, E., Méndez O., González J., Moreno M.; García D., Belén D., Medina, C., \& Ojeda C.; Griman N. (2010). Efecto del secado y tratamiento con ácido cítrico sobre la degradación de carotenoides en harinas de batata (Ipomoea batatas L.). Facultad Agronomía 27, 112-124.

- Sanchez, M., \& Rivera, L. (2018). Aplicación de dos modalidades de riego por goteo en el crecimiento y producción de camote (Ipomoea batatas L., variedad INIA 320). Anales Científicos 79 (1), 144 - 150 (2018).

- Software Analytics \& Solutions (SAS). 2014. Disponible en: https://www.sas.com/es_pe/trials.html

- Thomas R., \& Clark C. (1983). Populations dynamics of Meloidogyne incognita and Rotylenchulus reniformis alone and in combination, and their effects on sweetpotato. Journal of Nematology 15(2), 204-211.

- Villagómez, C.V. (2013). Publicación del Cultivo de Camote. Programa de Investigación en Raíces y Tuberosas. La Molina, Lima-Perú.

- Villalpando, J., \& Ruiz, A. (1993). Observaciones Agrometeorológicas y su uso en la agricultura. Editorial Lumusa, México. p. 133. 